\title{
LA VOZ DE SANTA VELA EN LAS MADRES NEGRAS, DE PATRICIA ESTEBAN ERLÉS
}

\author{
SANTA VELA'S VOICE IN LAS MADRES NEGRAS, \\ BY PATRICIA ESTEBAN ERLÉS \\ Claudia Cabrera Espinosa \\ Universidad Nacional Autónoma de México \\ claudiacabrera@filos.unam.mx
}

Recibido: 30.06 .2020

Aceptado: 23.02.2021

Resumen: La narrativa de Patricia Esteban Erlés ha otorgado, desde sus inicios, un fuerte peso a los espacios en donde se desarrolla la acción. Algunos de ellos se inspiran en inmuebles de novelas y películas, como ocurre en el caso de Manderley -la casona de la película Rebeca, de Hitchcock- y la mansión Winchester. El escenario principal de la novela Las madres negras, el convento de Santa Vela, es un elemento crucial para la conformación de lo gótico, lo siniestro y lo fantástico, rasgos que se combinan con maestría en esta obra. Este trabajo destaca las características arquitectónicas del espacio y su relación con la trama de la novela. Asimismo, se aborda el protagonismo del inmueble como un personaje, la importancia de su voz a lo largo de la novela y la proyección de la mente de su propietaria original en su construcción, con base en la teoría de Maria Tatar, Sigmund Freud, Anthony Vidler y Gaston Bachelard, entre otros.

Palabras Clave: Casas encantadas, fantástico, Esteban Erlés, Unheimliche

ABSTRACT: The narrative of Patricia Esteban Erlés has given, from the beginning, a strong relevance to the spaces where the action takes place. Some of them are inspired by the properties of novels and films, as in the case of Manderley -the mansion of the film Rebecca, by Hitchcock- and the Winchester Mistery House. The main setting of the novel Las madres negras, the convent of Santa Vela, is a crucial element for the conformation of the gothic, the sinister and the fantastic, features that are masterfully combined in this work. This paper highlights the architectural characteristics of the space and its relationship with the plot of the novel. It also approaches the protagonism of the building as a character, the im- 
portance of its voice throughout the novel and the projection of the mind of its original owner in its construction, based on the theory of Maria Tatar, Sigmund Freud, Anthony Vidler and Gaston Bachelard, among others.

KeYwords: Haunted Houses, Fantastic, Esteban Erlés, Unheimliche

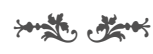

INTRODUCCIÓN

En la literatura fantástica, el espacio en donde ocurre la acción es determinante para la aparición de los fenómenos sobrenaturales. El paso de la literatura fantástica clásica a la moderna e incluso a la neofantástica, en términos de Jaime Alazraki, se distingue, entre otros aspectos, por el sitio en donde se desarrollan los acontecimientos (2001). Julio Cortázar, alejándose de esta tradición, describía en 1981 un tipo de relatos que le resultaban anacrónicos, en donde: "Todo sucede en viejas casas, en mesetas azotadas por el viento o en pantanos con vapores que invaden el horizonte" (González 1981: 42). Estos escenarios remotos e indeterminados ambientaron los relatos del género escritos durante los siglos XVIII y XIX, desde la publicación de El castillo de Otranto, de Horace Walpole, en 1764, cuyo título anticipa el peso que el espacio tendrá en la trama, y poco a poco fueron relevados por otros que el lector pudiera identificar e incluso recordar.

En el siglo $x x$ existe una diversidad de relatos en donde los recintos constituyen un elemento cardinal para la aparición del fenómeno sobrenatural, sin que estos se encuentren en parajes solitarios de poblados recónditos. Ejemplo de ello es "Casa tomada", del propio Cortázar, "There are more things", de Jorge Luis Borges, y "La casa de azúcar", de Silvina Ocampo, cuya acción transcurre en viviendas de sitios bien definidos: la calle Rodríguez Peña, el barrio de Turdera y la calle Montes de Oca, respectivamente, todos ellos en Buenos Aires. Dentro de la tradición española, "La casa de los dos portales", de José María Merino, es una muestra de cómo una residencia con una ubicación igualmente determinada -el cruce de la calle de la Torre y la de Padre Isla, en la ciudad de León- funciona como un umbral para la aparición del hecho sobrenatural. En años más recientes, "La casa de Adela", de Mariana Enríquez, describe un caso en el que un inmueble del barrio bonaerense de Lanús propicia la desaparición de una niña como una metáfora de los miles de desaparecidos durante la dictadura argentina. Estas referencias contribuyen a la construcción de la cotidianidad y del plano realista del relato que será irrumpido. Como afirma Patricia García, "En el texto fantástico el umbral, con sus múltiples variantes, es el motivo liminal por excelencia" (2013: 27). En estos casos, se trata de un umbral físico y tangible que, al ser cruzado, propicia la existencia de una serie de transgresiones. 
La construcción de la cotidianidad, sin embargo, no siempre es la base de las narraciones fantásticas. Ciertas obras literarias contemporáneas aún recurren a lo gótico para ambientar sus historias. En cuanto a las características arquitectónicas de este tipo de espacios, observamos castillos, pasadizos, sótanos y casas victorianas con mansardas y techos a dos aguas que recuerdan rostros humanos, es decir, estructuras que provocan temor y desasosiego en el lector. Rosa María Díez Cobo describe este tipo de inmuebles como "edificaciones de tejados inclinados, abuhardilladas, divididas en múltiples secciones y rincones, con disposiciones laberínticas y asimétricas" (2020: 141), y agrega que no son meros recipientes de hechos o personajes pavorosos, sino actores principales de las narraciones, cuestión que se retomará más adelante. Ana Abello, por su parte, apunta que esta arquitectura: "Se convierte en una herramienta discursiva que canaliza temas vedados, que de otro modo serían muy complicados de expresar en la sociedad en que se insertan" (2019: 33).

En Las madres negras, de Patricia Esteban Erlés, la presencia de lo gótico en el convento de Santa Vela, en donde ocurre la mayor parte de la novela, tiene un peso cardinal en la trama. Anthony Vidler afirma que la arquitectura ha estado íntimamente ligada a la noción de lo siniestro desde finales del siglo XVIII, que esta revela la profunda estructura de lo perturbador en más de una manera y demuestra el inquietante desfase entre lo homely y lo unhomely (1992: Ix). Abello señala al respecto: "Lejos de agotarse, las figuraciones góticas y fantásticas han perdurado en el tiempo, adaptándose al momento presente y aunando o intercambiando en muchas ocasiones sus preceptos" (2019: 34). En efecto, lo gótico se ha transformado y se ha alejado de lo terrorífico proveniente del exterior. Se ha interiorizado en el individuo y se muestra ahora desde un punto de vista psicológico.

En este trabajo se destacará la figura del convento de Santa Vela como una de las figuras protagónicas de la novela, y la manera en que su estructura y su historia se entrelazan con la trama de la obra. Asimismo, se expondrá la relevancia de la voz del recinto, así como sus características impresionistas y expresionistas de esta en contraste con otras obras afines, como La maldición de Hill House (1959), de Shirley Jackson. Para ello, se mencionarán otras viviendas relevantes en la obra de Esteban Erlés, como antecedente de su interés por la relación entre la trama de sus relatos y los espacios en donde se llevan a cabo, y nos basaremos en estudios de Sigmund Freud y Maria Tatar en torno a lo siniestro. Igualmente, nos apoyaremos en las investigaciones de Stephen Mariconda, Gaston Bachelard y Julio Caro Baroja sobre la mansión Winchester, el espacio y la presencia de los fantasmas en casas abandonadas, respectivamente.

\section{EL LADO SINIESTRO DE LAS VIVIENDAS}

En la narrativa de Esteban Erlés, quien combina lo fantástico con reminiscencias góticas, observamos una diversidad de personajes víctimas del abandono y la desgracia que pueblan una serie de recintos siniestros cuya descripción, y a veces incluso su carácter, están vinculados con la trama de los relatos. En cuanto a las características de los espacios, en la obra de la zaragozana estos siguen siendo 
lugares lejanos de ubicación indeterminada y rasgos muchas veces extravagantes, ajenos a la cotidianidad del lector actual. En palabras de Miriam López Santos, en la narrativa española contemporánea:

El castillo como recinto cerrado, casi herméticamente, dará paso a sanatorios, hospicios o mansiones, como nuevos espacios de la opresión, aislados geográficamente y marginados del conjunto de la sociedad, pero que se descubren como renovados escenarios de pesadilla. (López Santos 2009: 332)

Este es precisamente el caso de Las madres negras, en donde una antigua mansión ha sido convertida en convento. Además del tipo de espacios en donde transcurre la acción, lo gótico se relaciona con lo terrorífico. Como señala Inés Ordiz: "uno de los elementos primordiales de la narrativa gótica es su capacidad de representar y evocar el miedo, el horror, lo macabro y lo siniestro desde una perspectiva emocional más que racional" (2014: 145). Aunque las narraciones ya no ocurran en un pasado oscuro y remoto, agrega, los escenarios ficcionales se siguen construyendo con el fin último de engendrar horror.

En el famoso ensayo de Freud titulado "Lo siniestro", el médico austriaco opone lo Unheimliche -ominoso- a lo Heimliche -lo familiar, lo conocido-. Lo siniestro sería, entonces, lo extraño, que puede tornarse inhóspito y hostil. Resulta interesante que en dicho estudio los extremos terminan por tocarse, pues lo que en un principio parecería confortante y acogedor en muchas ocasiones revela un interior escabroso. De este modo, una vivienda que en principio debería resguardar a sus habitantes, puede convertirse en el escenario de una verdadera pesadilla.

En el artículo "The Houses of Fiction", la académica Maria Tatar relaciona por su etimología el término freudiano das Unheimliche con el papel de las casas en la narrativa fantástica. Dado que Heimliche proviene de Heimat, "hogar", su opuesto, Unheimliche, se vincula con lo que no es familiar y resulta ajeno. En este mismo sentido, das Unheimliche se ha traducido al inglés como the uncanny, pero también como the unhomely. Freud dedica buena parte de su ensayo a los matices y connotaciones de dicho vocablo, y queremos recuperar aquí el sentido de la casa (Heimat) como un ambiente familiar y acogedor, pero que al mismo tiempo esconde cosas para el resto de las personas. Cabe mencionar que la palabra alemana Heimliche comparte su raíz con Geheimnis, que quiere decir "secreto"; la familiaridad engloba, entonces, la idea de lo conocido y reconfortante, por un lado, y, por otro, la de un misterio que no debe desvelarse.

Tatar señala que los eventos siniestros - uncanny- tienen el poder de provocar temor precisamente porque son a la vez familiares y extraños: "A House contains the familiar and congenial, but at the same time it screens what is familiar and congenial from view, making a mistery of it" (1981: 169). ${ }^{1}$ Los misterios de un hogar, aunque ocultos para un observador externo, muchas veces pueden ser

\footnotetext{
1 Una casa contiene lo familiar y acogedor, pero al mismo tiempo oculta lo que es familiar y agradable de la vista, haciendo de ello un misterio.
} 
más peligrosos que las amenazas del mundo exterior. Para Rosie Jackson, esta revelación de lo extraño y lo misterioso:

Supone introducir zonas oscuras formadas por algo completamente 'otro' y oculto: los espacios que están más allá de la estructura imitadora de lo 'humano' y lo 'real', más allá del control de la 'palabra' y la 'mirada'. De ahí la asociación de lo fantástico moderno con el horror, de los relatos de terror gótico a las películas de horror contemporáneas. (Jackson 2001: 150)

Estas zonas oscuras se manifiestan en buena parte de los relatos de Esteban Erlés $y$, en algunos casos, tienen una correlación con el espacio que los contiene, como se verá más adelante. No obstante, Las madres negras es el mejor ejemplo de una estructura arquitectónica imitadora de lo humano, una expresión de lo sobrenatural, aquello que produce el verdadero horror.

\section{LA RELEVANCIA de LAS CASAS en la obra de Esteban ERLÉS}

La afición de Patricia Esteban Erlés por las viviendas y su papel como elementos activos de las narraciones puede rastrearse desde sus primeros cuentos. Debe destacarse que, como apunta Raquel de la Varga, la casa cobra una relevancia mayúscula "a partir de su relación con los personajes femeninos" (2019: 288), lo cual se aprecia tanto en Las madres negras como en una diversidad de relatos. "Historia de una breve alma en pena" (incluido en Manderley en venta) narra la historia de una niña que se ve obligada a pasar unos días del verano en una casa de pueblo, con su abuela, quien nunca se recuperó de la muerte de la tía Monsita y encuentra en su nieta cierta similitud con ella. Por eso, en cuanto la narradora hace su aparición, saca la ropa de la tía para que se la ponga: "Chaquetitas de punto con botones de nácar descascarillados para las tardes en que refrescara, vestiditos de nido de abeja y volantes que crujían" (Esteban Erlés 2008: 45). A partir de ese momento, la abuela comienza a llamarla Monsita y a tratarla como si fuera su hija. Al traspasar el umbral de la vivienda, la niña debe aceptar una serie de hechos que resultarían imposibles en un contexto distinto. En cuanto a la casa, la narradora afirma: "solo puedo decir que hubiera resultado bonita si no hubiera habido tanta tristeza atrapada entre sus paredes" (Esteban Erlés 2008: 46), líneas que adelantan que la abuela no es la única triste, pues la casa la acompaña en el sentimiento: "Era un edificio de tres plantas, que siempre se me antojó fantasmal, como un caballero elegante que nunca se hubiera recuperado de una gran tragedia y permaneciera de espaldas al mundo" (Esteban Erlés 2008: 46).

Estas descripciones ya acusan cierta antropomorfización de los espacios, sin embargo, hasta ahora solo se trata de la percepción de la narradora y del establecimiento de un símil entre el inmueble y un ser humano. Puede observarse en ellas el germen de lo que en obras posteriores será la total animación de los espacios. El relato recuerda a la novela Rebeca, de Daphne du Maurier -llevada a la pantalla grande por Alfred Hitchcock, en 1940-, en donde una mansión encierra la presencia de la primera esposa del protagonista, e incluso se hace una mención explícita de esta obra, pues una de las habitaciones -con una elegante cama con 
dosel y colcha de raso- le remite a la narradora al dormitorio de la protagonista de la escritora británica. Asimismo, el nombre de la residencia en donde se desarrollan las acciones de Rebeca, Manderley, le da título al libro de la zaragozana.

Otra vivienda peculiar y con una personalidad impetuosa dentro de la narrativa erlesiana es la descrita en "Azul ruso". Se trata de un viejo edificio "con aires de teatro cerrado", un conjunto de departamentos amueblados con reliquias de sus antepasados en donde vive Emma Zunz -nombre proveniente de un relato de Jorge Luis Borges-. En el cuento, la mujer aprovecha la visita de los vendedores que tocan el timbre para hacerlos pasar y convertirlos en gatos-como Circe, la hechicera a quien se enfrentó Ulises para evitar que lo transformara en animal en la isla Eea-, o bien solicita por teléfono servicios de plomería o albañilería para que le manden a alguien a hacer una reparación inexistente. Así, el inmueble está poblado por una diversidad de felinos. La ornamentación es por demás excéntrica: el portal está adornado con el rostro de un león taciturno, los departamentos se comunican por arcos y trampillas y están llenos de arpas y cortinajes, relojes parados y ángeles pintados en los techos.

La casa y la ciudad funcionan como personajes. Cuando uno de los hombres se dirige hacia la morada de Emma Zunz, mientras camina por la calle: "los pómulos esquinados de las estatuas parecían reprobarle la dirección de sus pasos" (Esteban 2010: 77). Sin embargo, el hombre continúa su camino y llega a su destino, al edificio a donde la compañía de seguros lo envió a reparar una claraboya, que ahora no es más que un ojo vacío que lo observa. Y también él es convertido en gato, en un azul ruso condenado a comer hígados de pollo y ronronear entre las faltas de su captora. Sobre esta afición a dotar a los inmuebles de sentimiento, Esteban Erlés ha escrito:

Yo soy de las que creen que las casas están vivas. Y que tienen su genio, apacible o endiablado, y que les puedes caer bien o mal, depende. Me he sorprendido a veces pensando "esa fachada parece feliz" o no he vuelto a pasar por ciertas calles con tal de no encontrarme con el ceño fruncido de algún edificio. (Esteban Erlés 2019: 77)

El libro de microrrelatos Casa de muñecas está dedicado por entero a una mansión de diez habitaciones: un cuarto de juguetes con muñecas fatales, un dormitorio con terrores nocturnos, una habitación con un efecto mariposa, un cuarto de baño con un espejo impertinente y un hombre en la bañera, un salón comedor con fantasmas, una cocina con platos envenenados, una biblioteca con leyendas, un desván de los monstruos, una cripta con tierra en los ojos y un exterior con un secreto. Tanto los elementos externos como los internos -ilustrados por Sara Morante- presagian los horrores que ocurren dentro: fotografías en sepia y blanco y negro, un piano, partituras de Mozart, un corpiño asfixiante, candelabros, vajillas de porcelana. En las distintas habitaciones retratadas, lo gótico -no necesariamente relacionado con lo sobrenatural- hace su aparición como una clara intención de provocar desasosiego y terror. En algunos casos, lo fantástico también está presente, como los juguetes que dialogan con sus propietarios. Como observa Ordiz, en la literatura gótica la idea del miedo no tiene que ver con 
el susto o el espanto físico, sino "con un terror intrínseco causado en el lector ante la presencia de los acontecimientos ominosos, sean o no sobrenaturales" (2014: 154). La Casa de muñecas de Esteban Erlés, que combina lo extraño y lo fantástico, te devuelve la mirada y en ella todo está vivo; en ella todo bulle: los armarios, los retratos, los espejos con hombres atrapados, los jabones con forma de niño.

Es en Las madres negras, sin embargo, en donde apreciamos una mayor profundidad en cuanto a la personalidad e intimidad de la vivienda; en donde la familiaridad que debería encerrar el inmueble se convierte en lo Unheimlich; en donde las paredes hablan. En ella se describe la llegada de las huérfanas al convento Santa Vela en medio de la oscuridad y el silencio, cómo les cortan el cabello a rape y las obligan a llevar un incómodo vestido gris en las heladas habitaciones en donde ingieren sus frugales alimentos. Cada capítulo del libro cuenta la historia de un habitante de Santa Vela y sus inmediaciones y, por supuesto, la del convento. Niñas que sobrevivieron a la peste, niñas-brujas, niñas cuya familia las rechazó por lo abrumador de su belleza, monjas solitarias que encuentran en la grandeza de los libros un motivo para seguir viviendo.

La llegada de las niñas al convento es desgarradora. Entran luchando por librarse de las manos de las monjas y, una vez dentro, se les castiga por su falta de mansedumbre. Se les despoja de su nombre y se les otorga el de una virtud sin que ellas comprendan por qué las han metido ahí dentro. Antes de conocer a sus compañeras pasan por un angustiante primer encierro, aun creyendo que alguien irá a rescatarlas:

No se atrevía a moverse en ese cuarto horrible en el que sentía que un animal enfermo y maligno respiraba cerca de ella. Pero su padre no vino y Coro lloró, sintió hambre y frío, se durmió y lloró en sueños y sintió la misma hambre y el mismo frío en su pesadilla y oyó de nuevo el respirar fatigado del monstruo al que no podía ver, tendido en una esquina. (Esteban Erlés 2018: 69)

La infancia de las habitantes del convento transcurre entre la humedad y el frío, el temor y la incomprensión, los intentos de escape y las reprimendas, y a cada página va emergiendo lo siniestro. Cuando se le preguntó a la autora por su infancia, en una ocasión, ella respondió que fue un lugar extraño: "La tristeza y la oscuridad se adueñaban a veces de la casa y entonces yo quería crecer, dar una patada en el fondo y salir de la niñez porque me sentía indefensa. La infancia era, como dice Ana María Matute, más larga que la vida" (Castro 2018). Esa sensación de indefensión es la que se transmite a lo largo de la novela, en la que las niñas no son dueñas de sus actos y deben seguir las órdenes de un grupo de monjas que tampoco saben a ciencia cierta a quién obedecen, pues en muchos momentos Dios parece darles la espalda.

Sobre una de las inspiraciones de Santa Vela, Esteban Erlés ha comentado: “De pequeña visité en una convivencia el convento de clausura de la Puerta del Carmen y me parecía que era un ser vivo dispuesto a engullir a las mocosas que se acercaran demasiado" (Castro 2018). El convento se convierte, entonces, en una amenaza más tanto para las huérfanas como para las monjas. Y es que la casa, como todas las casas espeluznantes en donde pasan cosas siniestras, tiene 
un secreto. Antes de convertirse en Santa Vela, el inmueble fue una de las propiedades de Larah, la joven esposa de Der Corven, fabricante de armas, quien murió poco después de su boda durante la prueba de un rifle. Larah todavía alcanzó a ver a su amado con la mitad del rostro deshecho por la bala y, entre la locura y el delirio, perseguida por las voces de los soldados muertos por las armas fabricadas por su familia, se refugió en la mansión con una maldición a cuestas, y la convirtió en un refugio imposible con decenas de habitaciones, sótanos y pasadizos y un solo espejo, vuelto al revés para siempre.

Esteban Erlés es heredera de Shirley Jackson, a quien dedica la novela y llama "señora de todas las casas encantadas" (2018: 9). La escritora californiana, autora de La maldición de Hill House (1959), pone en boca de uno de sus personajes las siguientes líneas:

Hill House no ha sido apta para que nadie la habitase durante más de veinte años. Cómo era antes de este momento, si su carácter fue moldeado por la gente que vivió aquí o por lo que hicieron, o si era malvada desde su origen, son preguntas que no puedo contestar. (Jackson 2018: 65)

La mansión tiene un carácter propio y los sucesos del relato se entrelazan con los espacios. La novela de Jackson ha sido celebrada, entre otras cosas, porque introduce al lector en la mente y los temores de los personajes, más allá de describir una sucesión de hechos terroríficos. La mansión se convierte en un personaje con una historia y una naturaleza propias: "Es cierto que existen sitios que atraen inevitablemente una atmósfera de santidad y bondad; puede que, por consiguiente, no resulte demasiado arriesgado decir que algunas casas son malas de nacimiento" (Jackson 2018: 65). Tanto Jackson como Esteban Erlés presentan la existencia de la casa como un actor de sus narraciones, por lo que esta se levanta como un elemento activo de la trama y no como un mero escenario.

\section{El convento de SANTA Vela}

En Las madres negras, la autora zaragozana ha llevado el papel de la casa más allá del de un personaje, lo cual ya es ciertamente transgresor; ha profundizado en su psicología y le ha otorgado una voz que siente y reflexiona sobre su propia condición. El germen de esta historia, que se convierte en el secreto de Santa Vela, tiene el mismo origen que La maldición de Hill House: la mansión Winchester. Esta familia desarrolló y comercializó a mediados del siglo xIX el rifle de repetición que lleva su nombre, el cual hizo posible matar una mayor cantidad de nativos. Al enviudar, y atormentada por el sentimiento de culpa, Sarah Winchester contacta con un médium, quien "le comunicó un deseo de su esposo desde el más allá: debía construir una casa cuyas sucesivas ampliaciones le permitieran escapar de los espíritus furibundos de los indios abatidos por los rifles de su familia" (Esteban Erlés 2019: 78).

Las similitudes entre Larah y Sarah son tan evidentes que Esteban Erlés solo le cambió una letra al nombre al bautizar a su personaje. En cuanto al parecido de las viviendas, la de Santa Vela dice sobre sí misma: "Al fin y al cabo, soy una 
casa de doscientos años, tengo doce desvanes, cuarenta y siete chimeneas y casi mil ventanas" (Esteban 2018: 28). La mansión Winchester, por su parte, es descrita en Fondo de armario de la siguiente manera:

Casi doscientas habitaciones, diez mil ventanas, escaleras que suben a ninguna parte y puertas detrás de las cuales solo hay una pared son el resultado de su huida hacia adelante para escapar del pasado de su fortuna, cada vez mayor y más terrible, como la propia mansión en la que se refugió hasta su muerte. (Esteban Erlés 2019: 78)

Steven Mariconda (2007: 276) ofrece aún más detalles sobre esta residencia cercana a la ciudad de San José de California, y señala que intervinieron en ella carpinteros y albañiles hasta la muerte de Sarah, treinta y ocho años después de iniciada la ampliación. William y Sarah se casaron en 1862 y tuvieron una hija que murió en 1866. La viuda, quien perdió a su marido en 1881, compró la propiedad en 1884 y pretendía confundir a los espíritus mediante una serie de pasillos y habitaciones laberínticos. En 1906, año del terremoto de San Francisco, la Casa Winchester era una mansión victoriana gótica de siete pisos con quinientas habitaciones, y parte del inmueble se vino abajo. Cuando Sarah murió, en 1922, la casa tenía ciento sesenta habitaciones, dos mil puertas, diez mil ventanas, cuarenta y siete escaleras, cuarenta y siete chimeneas, trece baños y seis cocinas. Aún se conservan más de siete mil metros cuadrados de habitaciones de ángulos obtusos, escaleras que no conducen a ningún lado, pasajes secretos, puertas y ventanas que se abren a paredes. Stephen King se inspiró en ella para escribir la miniserie Rose Red, de 2002, y en 2018 se estrenó la película La maldición de la casa Winchester, dirigida por los hermanos Michael y Peter Spierig.

Si bien las casas de Sarah Winchester y Larah Corven no son estructuralmente idénticas, tienen en común la proyección de la mente de sus creadoras en la arquitectura de las viviendas. En Fondo de armario, Esteban Erlés se plantea "hasta qué punto los lugares en los que hemos vivido no son un doble nuestro, con sus ventanas sonrientes, sus pasillos interminables y un oscuro sótano al que da miedo asomarse" (2019: 78). El convento de Santa Vela, al igual que la mansión Winchester, es un reflejo de la mente perturbada de su propietaria, Ilena de recovecos y habitaciones para perderse, $y$, al igual que ella, también tuvo un pasado esplendoroso. En Las madres negras, el inmueble rememora mientras escucha el cuchicheo de las niñas:

... antes de que yo fuera Santa Vela, cuando todavía los viajeros sonreían y se detenían un momento a admirar los tejadillos triangulares, rojos como sombreros infantiles, de las dos torres laterales. Cuando aún había quien quería contemplar mi grandeza sencilla, el aire de novia que espera a su amor ante el altar de mi fachada de piedra joven". (Esteban Erlés 2018: 35)

De esta manera se describen el crecimiento de la casa, sus cambios, su envejecimiento, del mismo modo en que se ha narrado la historia de Larah antes de su llegada, cuando su vida aún tenía un sentido y no era un amasijo de paranoia y 
soledad. El sótano al que se refiere Esteban Erlés, el cofre que guarda su oscuro secreto, es el de la mujer y su familia, el cual otorga a la atmósfera un aire siniestro y el elemento fantástico a la narración: la voz de la vieja mansión que todo lo ve. Díez Cobo apunta sobre las percepciones de las viviendas que "la casa maligna es aquella en la cual, con tan solo un primer golpe de vista, sabemos que nos encontramos ante un organismo sintiente, ante un ente enfermo y al acecho de aquellos que osen cruzar su umbral" (2020: 141). Santa Vela es un ejemplo magnífico de la decadencia de un inmueble que, como si fuera un ser humano, ha envejecido hasta el punto de mudar su carácter y mostrarse como un ente amargado y malicioso.

En La poética del espacio, Gaston Bachelard (1965: 35) plantea la existencia de la casa como el no-yo que protege al yo. Esta es definida como un espacio cuyos límites son sensibilizados por el ser amparado. Su beneficio más precioso, agrega, es que alberga el ensueño y protege al soñador. Esta idea del hogar como un ente protector también está presente en Mariconda, quien afirma: "A house provides a sense of containment, of enclosure, warmth, protection from the elements, a sense of intimacy and nurture. As such, it is an extension of the Mother archetype" (2007: 268). ¿Qué pasa, entonces, cuando la casa no tiene a quien amparar? ¿Quiénes viven en ese espacio cuando sus habitantes la abandonan o mueren? ¿Es posible que las atmósferas que antaño fueron ocupadas por seres humanos permanezcan habitadas por la reminiscencia de su espíritu o por fuerzas capaces de transformar la realidad? En Las madres negras, la respuesta parece ser afirmativa. Las almas de los asesinados acompañan a Larah y dan pie a un ambiente siniestro y demencial en un sitio que debería ser empático y maternal. Cuando ella muere, su alma permanece en el inmueble, sin embargo, este parece echar de menos a su antigua moradora: "Pobre Larah, se dolía la casa al recordarla. Llevaba tantos días huyendo que se desmayó de pura fatiga ante mi puerta" (Esteban Erlés 2018: 29). Es relevante que el paso de la mujer por Santa Vela permanece tanto en la arquitectura caprichosa de la construcción como en el recuerdo del inmueble.

Steven Mariconda (2007: 269) señala que la estructura básica del relato de la casa encantada parte del asesinato de una persona dentro de esta, o bien, cuyos restos fueron depositados en ella. El espíritu del fallecido ronda por la vivienda, sobre todo por las noches, hasta que alguien descubre la causa del encantamiento y sigue al espectro hasta el sitio en donde yacen los restos. Después de que a estos se les da sagrada sepultura, el fantasma puede descansar en paz. Este es uno de los motivos recurrentes de la literatura gótica y puede rastrearse en textos antiquísimos. Caro Baroja (1990: 1), en un afán de ejemplificar la transmisión de leyendas a lo largo de grandes distancias, refiere el caso de una residencia en donde vivía un fantasma que no desaparece hasta que se encuentran sus restos y son enterrados. Esta historia se encuentra en el Jardín de flores curiosas, de Antonio de Torquemada, del siglo xvi, pero se halla también "punto

2 Una casa proporciona una sensación de contención, de encierro, de calor, de protección de los elementos, un sentido de intimidad y cuidado. Por lo tanto, es una extensión del arquetipo de la Madre. 
por punto, episodio por episodio" (Caro 1990: 1), en las Cartas de Plinio el Joven, como hecho ocurrido al griego Atenodoro en tiempo de Domeciano, en el siglo II. El historiador finaliza el asunto señalando que ya en el siglo XIX, e incluso en el $\mathrm{xx}$, el problema de las casas habitadas por fantasmas se convirtió en un problema jurídico, puesto que en Italia se establecieron normas sobre lo que tenía que hacerse en caso de que una vivienda debiera ser abandonada por este motivo, y que existieron pleitos debido a que un propietario no advirtió a su inquilino sobre una situación de este tipo.

En el presente narrativo de la novela de Esteban Erlés, sin embargo, el encantamiento de la casa no está determinado por la existencia de un alma en pena, sino por la animación de la residencia. No tenemos noticia de espíritus que se aparezcan en el convento, pues su presencia -la de los asesinados por los rifles Corven- es anterior. En su camino hacia la casa, Larah se encuentra con Lobelia y esta le dice que alguien quiere comunicarse con ella. Más adelante, los muertos hablan por su boca: "'Vete lejos.' [...] 'Iremos tras de ti' [...] 'Te encontraremos allá donde vayas.' 'Vete con tu maldición y reza mucho. Reza por nosotros'" (Esteban Erlés 2018: 35). A raíz de ello, la paranoia y la demencia de Larah propiciaron la construcción de un inmueble absurdo y dieron pie a que este cobrara vida. La mujer eventualmente murió y abandonó la propiedad, pero las paredes y la memoria de Santa Vela aún conservan su dolor y lo transmite a sus habitantes. Las características estructurales del convento son proyecciones de la mente perturbada de Larah, con quien tiene un vínculo muy estrecho. Vidler (1992: 69) establece una relación entre la arquitectura y el cuerpo humano desde épocas remotas -Vitruvio elabora una detallada analogía entre ambos-; no obstante, en Las madres negras las caprichosas construcciones del inmueble corresponden, sin duda, a la psique de su creadora.

En el capítulo dedicado a la hermana Tilda, amante de los libros, se confirma la existencia de los aparecidos en la mansión, quienes, aunque no murieron en ella, persiguieron a Larah para vengarse de la familia. Se narra que, en su lecho de muerte, la mujer firmó un pliego amarillento cediendo la residencia a las monjas del orfanato vecino, el cual había ardido tres veces en las últimas décadas. Y solo de esta manera se libera a la casa de su desgracia. Una vez más hace su aparición lo siniestro mediante la descripción del incendio y de "las cabelleras chamuscadas de las niñas y la voluntad inquebrantable de las monjas que salvaron a las que pudieron de entre las Ilamas" (Esteban Erlés 2018: 84). Tras la firma del documento, los espectros finalmente emprenden la retirada: "De pie junto a la puerta del dormitorio varios de aquellos guerreros destrozados por las balas en varias batallas la miraron abandonarse al sueño. Luego se santiguaron solemnes y emprendieron su agotador regreso a ninguna parte" (Esteban Erlés 2018: 8485). De este modo, se cierra el ciclo del primer hecho sobrenatural de la novela.

\section{LAS PAREDES HABLAN}

El convento funciona como la piedra angular de Las madres negras, y la existencia de su voz resulta cardinal para el desarrollo de esta, pues cuenta su propia 
historia, que es, en realidad, la historia de su creadora: Larah Corven. Díez Cobo apunta que la sujeción de la mujer al espacio doméstico ha hecho que este se convierta en un "alter ego perturbado de sus moradoras" (2020: 144), lo que indudablemente ocurre en la novela de Esteban Erlés. Por ello, cuando Santa Vela desvela su secreto, este es, en realidad, el de Larah, y de este modo se revela lo siniestro del espacio. Como señala Schelling: "Se denomina Unheimliche todo lo que, debiendo permanecer secreto, oculto... no obstante, se ha manifestado" (Freud 2008: 17). La voz del inmueble, asimismo, junto con las voces de los muertos por las balas Corven, inserta esta obra dentro de la tradición fantástica -pues de otro modo sería considerada dentro de lo "extraño"-, mientras que el carácter de lo narrado le otorga el matiz de lo siniestro. De la Varga observa un hibridismo genérico en la novela y apunta que en ella: "Lo maravilloso, el realismo mágico y lo fantástico se combinan y hasta se solapan, todo ello inserto en una ambientación repleta de infinidad de motivos góticos" (2019: 289); no obstante, si bien el plano de lo real está plagado de elementos inusuales y siniestros, la narración de Santa Vela constituye una transgresión en el discurso del relato -la otra será la participación de Dios en la trama-, ilegalidad que dará pie a lo fantástico. El convento es el único testigo de los hechos acontecidos en aquel sitio antes del presente narrativo: "La casa estaba ahí desde siempre, con su larga memoria de piedra" (Esteban Erlés 2018: 29). E incluso en los capítulos en los que se vuelve a la omnisciencia, Santa Vela es percibida como una entidad viva: "ella [Mida] oía cómo la casa respiraba de noche" (180).

Este recurso resulta insólito, en primer lugar, porque es inusual que en las narraciones se les otorgue voz a los objetos. Si bien algunos cuentos de Francisco Tario -"La noche del féretro" o "La noche del buque náufrago", entre otros- o ciertos capítulos de Me llamo rojo, de Orhan Pamuk, son ejemplos de ello, se trata de un punto de vista narrativo que continúa asombrando al lector, especialmente si este cambia dentro de la misma novela. En Las madres negras, Santa Vela es de los pocos personajes que tienen voz propia, fuera de los escasos diálogos de las niñas. El resto de los capítulos, concernientes a Mida, Coro o la hermana Priscia, son referidos por un narrador omnisciente. Otro de los seres que se manifiesta mediante la palabra es Dios: "Dios es Dios y suele hablar de sí mismo en tercera persona. [...] Dios no puede dedicar mucho tiempo a cada una de sus criaturas, precisamente porque Dios tiene todo el tiempo, y esa es su enfermedad, la más grave" (Esteban Erlés 2018: 37). Resulta curioso que este personaje no emplee la primera persona; el lector debe asumir que este nuevo narrador, aparentemente omnisciente, es un ser todopoderoso que ha optado por la impersonalidad. Se trata, entonces, de un juego entre la omnisciencia del narrador y la del protagonista de este capítulo. Como afirma Patricia Martínez:

La alternancia de puntos de vista y de voces narrativas incide en la forma de la novela, actuando estos como principios compositivos que delimitan el contenido y la configuración de la misma, determinando las leyes de coherencia interna y de verosimilitud que rigen la narración en función de lo que desde el ángulo y el narrador escogidos puede decirse, verse o saberse. (Martínez 2002: 200) 
La estructura de Las madres negras es, sin duda, uno de sus mayores aciertos, pues permite el acercamiento del lector al convento desde una diversidad de perspectivas $y$, en cada una de ellas, expone la relación entre el protagonista del capítulo y el espacio que constituye el corazón de la obra. La mayoría de los capítulos -veinticuatro de veintiséis- están narrados desde un punto de vista omnisciente y relatan las experiencias de las mujeres y niñas que viven o han vivido en Santa Vela, o bien, describen el vínculo de algunos personajes secundarios con el recinto. Los otros dos son los testimonios del convento mismo y de Dios. De todos ellos, Santa Vela es la única que se expresa en primera persona, por eso no sorprende que se le haya otorgado una sensibilidad, física y espiritual, como se desprende de las siguientes líneas:

No es fácil estar en todas partes al mismo tiempo cuando te duele cada vidrio roto del ala norte tras una tormenta. Soy un enorme cuerpo viejo y cansado. Un cuerpo absurdo, lleno de miembros trasplantados por la locura de una mujer que huyó también, no hacia afuera, como la muchacha de la que hablan las huérfanas, sino hacia adentro, hacia mi interior ... (Esteban Erlés 2018: 28)

Como se ha visto, el convento de Las madres negras adquiere un carácter propio que va más allá de la antropomorfización de un objeto. En términos de Elise Richter, la novela de Esteban Erlés conjuga el impresionismo y el expresionismo literarios. La filóloga austriaca expone que, mientras el impresionismo es: "la reproducción de la impresión de las cosas" (Richter 1956: 52), el expresionismo "es la reproducción de representaciones o de sensaciones provocadas en nosotros por impresiones externas o internas, sin que entren en consideración las propiedades reales de los objetos (de representación) que suscitan tales impresiones" (Richter 1956: 78). De este modo, cuando el narrador expresa: "La casa somnolienta veía cómo las niñas se dispersaban de pronto" (Esteban Erlés 2018: 26) denota la existencia de un animismo en la narración. La descripción no alude a cómo es la vivienda objetivamente, sino cómo aparece al ojo del observador, como ocurre también, por ejemplo, en La maldición de Hill House, cuando Jackson escribe: "No somos nosotros los que esperamos, sino la casa -repuso Eleanor-. Creo que está tomándose su tiempo" (2018: 141). En ambos casos se describe la impresión que los narradores tienen de un objeto inerte: una casa somnolienta; otra que se toma su tiempo. El lector asiste a la vivificación de las cosas, en la que, en palabras de Richter: "la diferencia entre el acaecimiento inanimado y el animado -entre el suceder y el hacer- se borra por completo" (1956: 59). En cambio, cuando Esteban Erlés pone en boca de Santa Vela las siguientes líneas: "Soy, lo sé bien, una mansión maldita, la casa de la historia más triste de todas" (2018: 28), no se trata simplemente de una personificación o de una impresión. Asistimos a la expresión del pensar y el sentir subjetivos del convento mismo. Como apunta Richter: "El artista expresionista no dice lo que ocurre o lo que ve, sino lo que a él le conmueve a la vista de un acontecimiento o de una cosa; expresa su sensación personal y su juicio (en ocasiones, su prejuicio) sobre las cosas" (1956: 78). En Las madres negras, el convento aparenta ser un ente vivo con emociones, pero además comunica historias y sentimientos y reflexiona sobre lo que ocurre en su 
interior. Se yuxtaponen impresionismo -lo referente a la apariencia- y expresionismo -lo especulativo e intuitivo- en una obra cuyos lindes internos fluctúan de un capítulo a otro.

\section{CONCLUSIÓn}

Desde los primeros libros de relatos de Patricia Esteban Erlés asistimos a una antropomorfización de las estructuras arquitectónicas. Cuentos como "Manderley en venta", "Azul ruso" o los microrrelatos contenidos en Casa de muñecas son representativos de esta caracterización. En Las madres negras, la autora acude a la tradición gótica para presentar un escenario laberíntico y poblado de fantasmas en donde el espacio no solamente presenta ciertas actitudes humanas, sino que logra expresar los temores y los dolores propios de nuestro género. Las criaturas que alberga, de manera análoga, padecen el sufrimiento del recinto y buscan liberarse de él. En Santa Vela se tocan los extremos de lo Heimliche y lo Unheimliche, pues constituye para sus habitantes tanto su única posibilidad de refugio, como una amenaza constante.

La voz del convento se alza como una añoranza y como una advertencia. Las características impresionistas de su narración, pero sobre todo las expresionistas, contribuyen al cariz fantástico de la novela, pues animan un objeto inerte que llega a adquirir protagonismo. Esta característica de la obra, junto con la estructura arquitectónica y la historia del sitio en donde se desarrolla la acción, así como el desvelamiento del secreto que debía permanecer oculto, otorgan un carácter siniestro a la narración.

A lo largo de la trama, el lector asiste al paso de lo homely a lo unhomely, sobre todo en la metadiégesis referente a su propietaria original. La existencia de las almas en pena que abandonaron Santa Vela tras la muerte de Larah también son elementos que conforman el terror en la novela, cuyos hechos sobrenaturales irrumpen en un plano realista que por sí mismo ya era bastante perturbador. La mezcla de lo gótico y lo fantástico en Las madres negras da como resultado una obra inquietante e inusual que toca todas las fibras del lector. Gracias a la complejidad de la estructura y a la diversidad de historias y voces discursivas, Patricia Esteban Erlés presenta una narración caleidoscópica que permite conocer la profundidad de la naturaleza humana.

\section{OBRAS CITADAS}

Abello Verano, Ana (2019). "Cartografías de lo sobrenatural. Imaginería de terror gótico en la narrativa breve de Patricia Esteban Erlés", Dicenda. Estudios de Lengua y Literatura Españolas, 37: 31-39.

Alazraki, Jaime (2001). "¿Qué es lo neofantástico?", in Teorías de lo fantástico, ed. David Roas. Madrid: Arco Libros, 265-282.

Bachelard, Gaston (1965). La poética del espacio. México: Fondo de Cultura Económica. 
Caro Baroja, Julio (1990). "Localización, personificación y personalización de las leyendas", Gazeta de Antropología, 7: 1-6. <http://www.ugr.es/ pwlac/G07_01Julio_Caro_Baroja.html> (20 de agosto de 2019).

Castro, Antón (2018). "Patricia Esteban Erlés, escritora: 'Me fascinan las sombras desde pequeña'", Heraldo (17 de enero). <www.heraldo.es/noticias/ocio-cultura/2018/01/ 17/patricia-esteban-erles-escritora-fascinan-las-sombras-desde-pequena-1219425-1361024.html> (6 de mayo de 2020).

De la Varga Llamazares, Raquel (2019). "Figuraciones de la femme fatale en Las madres negras de Patricia Esteban Erlés", in Realidades fracturadas. Estéticas de lo insólito en la narrativa en lengua española (1980-2018), ed. Natalia Álvarez Méndez y Ana Abello Verano. Madrid: Visor, 287-303.

Díez Cobo, Rosa María (2020). "Arquitecturas del hogar invertido: Reescribiendo la casa encantada", Brumal. Revista de investigación sobre lo fantástica, VIII.1: 135-156. <https://ddd.uab.cat/pub/brumal/brumal_a2020v8n1/brumal_a2020v8n1p135. $\mathrm{pd}>$ (6 de mayo de 2020).

Esteban Erlés, Patricia (2008). Manderley en venta. Zaragoza: Tropo.

Esteban Erlés, Patricia (2010). Azul ruso. Madrid: Páginas de Espuma.

Esteban Erlés, Patricia (2018). Las madres negras. Barcelona: Galaxia Gutenberg.

Esteban Erlés, Patricia (2019). Fondo de armario. Zaragoza: Contraseña.

Freud, Sigmund (2008). "Lo siniestro", in El hombre de la arena de E.T.A. Hoffmann. Trad. L. López Ballesteros. Palma de Mallorca: José J. de Olañeta.

García, Patricia (2013). "La 'frase umbral', desliz al espacio fantástico", in Visiones de lo fantástico (aproximaciones teóricas), ed. David Roas y Patricia García. Málaga: e.d.a. González Bermejo, Ernesto (1981). Conversaciones con Cortázar. Barcelona: Edhasa.

Jackson, Rosie (2001). "Lo oculto de la cultura", in Teorías de lo fantástico, ed. David Roas. Madrid: Arco Libros, 141-152.

Jackson, Shirley (2018). La maldición de Hill House. México: Penguin Random House.

López Santos, Miriam (2009). "Los viejos fantasmas vuelven al presente: lo gótico en la literatura española actual", Estudios Humanísticos. Filología, 31: 321-334.

Mariconda, Steven, J. (2007). "The Haunted House"., in Icons of Horror and the Supernatural: An Encyclopedia of our Worst Nightmares, ed. S.T. Joshi. Westport: Greenwood Press, 267-305.

Martínez García, Patricia (2002). "Algunos aspectos de la voz narrativa en la ficción contemporánea: el narrador y el principio de incertidumbre", Thélème. Revista Complutense de Estudios Franceses, 17: 197-220.

Ordiz Alonso-Collada, Inés (2014). "Estrategias ficcionales de lo insólito: la literatura gótica frente a la literatura fantástica", Badebec, 3.6: 138-168.

Richter, Elise (1956). "Impresionismo, expresionismo y gramática", in El impresionismo en el lenguaje, ed. C. Bally, E. Richter y R. Lida, trad. Amado Alonso y Raimundo Lida. Universidad de Buenos Aires, 45-103.

Tatar, Maria (1981). "The Houses of Fiction: Toward a Definition of the Uncanny", Comparative Literature, 33.2: 167-182.

Vidler, Anthony (1992). The Architectural Uncanny: Essays in the Modern Unhomely. Massachusetts: MIT Press. 